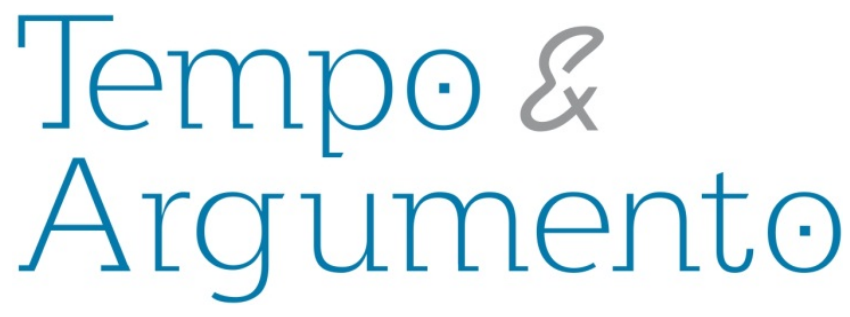

\title{
Professores de história: o uso do computador na construção do conhecimento histórico escolar
}

\begin{abstract}
Resumo
A presente discussão combina uma reflexão teórica e metodológica para compreender como o computador vem sendo utilizado no ensino de história, em escolas públicas e particulares, no ensino fundamental e médio. O artigo tem como referência a prática de professores de história em Londrina e região, no estado do Paraná. Foram abrangidas 18 cidades e investigadas 61 escolas, sendo 49 do sistema público e 12 pertencentes ao ensino particular. A investigação, com base em questionários respondidos pelos professores, possibilitou identificar as principais questões relacionadas à inserção das novas tecnologias no ensino de história e refletir sobre as possibilidades e limites de sua utilização. Além disso, permitiu sublinhar a importância da formação continuada de professores para tal inserção e refletir sobre ela. A preocupação central do trabalho reside na identificação de como e em que medida tal utilização conseguiu contribuir para alcançar os objetivos da disciplina, que é de propiciar aos alunos a condição de pensar historicamente, problematizando sua condição de ser social dentro de seu próprio momento histórico.
\end{abstract}

Palavras-chave: História - Estudo e Ensino; Professores de História.

\author{
Cyntia Simioni França \\ Doutoranda em Educação pela Universidade \\ Estadual de Campinas - Unicamp. Mestre \\ em História Social pela Universidade \\ Estadual de Londrina - UEM. Professora da \\ Universidade Norte do Paraná - UNOPAR \\ Brasil \\ cyntiasimioni@yahoo.com.br
}

\section{Cristiano Biazzo Simon}

Pós doutor pela Universitat Autònoma de Barcelona. Doutor e Mestre em História Social pela Universidade de São Paulo - USP.

Professor da Universidade Estadual de Londrina - UEL Brasil simon@uel.br

\footnotetext{
Para citar este artigo:

FRANÇA, Cyntia Simioni; SIMON, Cristiano Biazzo. Professores de história: o uso do computador na construção do conhecimento histórico escolar. Revista Tempo e Argumento, Florianópolis, v. 6, n. 12, p. 186 - 211, mai./ago. 2014.
} 


\title{
History teachers: the use of computers in the construction of educational historical knowledge
}

\begin{abstract}
In the present paper a discussion concerning theoretical and methodological reflections was made, in order to comprehend how computers have been used in history teaching, in public and private schools, elementary and high school in the region of Londrina, Parana state. Eighteen cities were covered; forty-nine schools from public system and twelve from private system were investigated. Researches from questionnaires completed by teachers enabled us to identify the main issues related to inclusion and also to reflect on the possibilities and limits of the use of new technologies during the history teaching process. Moreover, it also enabled us to emphasize the importance of continued training of teachers for such insertion. The main concern of the work was to identify how and in which steps such use has been able to contribute to achieving all the objectives of the subject, based on providing students conditions for the development of a historical thinking, discussing their condition of being social from historicity.
\end{abstract}

Keywords: History - study and teaching, History teachers. 


\section{Introdução}

Diante das transformações tecnológicas, surgem novas exigências sociais, refletindo-se na educação, impondo questionamentos sobre o papel da escola. Duas grandes preocupaçõesnessa direção, aqui colocadas em forma de indagações, nortearam a presente reflexão; a ela se imbricam e com ela dialogam, a saber: Como as novas tecnologias (em especial o computador) foram incorporadas à escola? No caso específico desta pesquisa, como essa ferramenta pedagógica pode contribuir no ensino de história?

Sendo a escola um local de construção do conhecimento, socialização do saber e troca de experiências, tal situação coloca a necessidade de debates entre educadores e equipe pedagógica para a incorporação, de forma crítica, do computador no ensino.

Lembrando que a instituição escolar deve estar à frente em uma sociedade em que as informações são ultrapassadas num curto espaço de tempo, "não se pode admitir que justamente a escola, local onde se produz conhecimento, fique à margem da maior fonte de informações disponíveis e, mais, não seja capaz de orientar sua utilização" (FERREIRA, 1997, p. 87).

Este pressuposto implica práticas pedagógicas focadas não apenas nos conceitos disciplinares, mas na pesquisa e seleção das informações adquiridas para a resolução de problemas ligados ao seu contexto social, bem como à produção do conhecimento escolar de história. Portanto, exige-se um repensar do ensino de história, incompatível com memorização, repetição de fatos e a condição do professor como exclusivo detentor do saber.

Sabe-se que a incorporação dos computadores na escola altera os papéis dos professores e, consequentemente, dos alunos, de acordo com a afirmação de Bittencourt (2004), segundo o qual os alunos estabelecem comunicações interativas e mudanças culturais que geram indivíduos com diferentes potencialidades de compreender a sociedade em que vivem.

Neste sentido, as novas linguagens, imersas na sociedade, possibilitam novas formas de leitura; entretanto, o computador não pode ser visto apenas como um dos maiores veículos de transmissão de informações, mas como ferramenta pedagógica no 
Convém lembrar que, como qualquer outro recurso tecnológico, este deve ser entendido como um dos meios alternativos para construir o conhecimento escolar de história, visto que propicia aos sujeitos se interligar com o mundo, possibilitando escolas menos autoritárias, cedendo lugar a ambientes de aprendizagem mais estimuladores e criativos, desde que submetidos a um olhar crítico, forem considerados apropriados. Desde a década de 1970, existem propostas de modernização do ensino apoiadas na utilização das tecnologias de comunicação e informação (TIC), como televisores, rádios, videocassetes, retroprojetores e informática. Nas instituições escolares, contudo, sua implementação e utilização estava embasada quase toda em concepções tecnicistas.

Até meados de 1980, as tecnologias eram entendidas majoritariamente pela função de aperfeiçoar o processo de ensino, colocadas como recursos didáticos de apoio ao professor, por serem mais dinâmicas e atrativas do que a aula expositiva e o clássico uso do quadro de giz. Nessa perspectiva, propunha-se acabar com as falhas da educação, baseada em transmissão de informações do professor para o aluno. Assim, as máquinas, pela capacidade de armazenamento de informações, eram vistas como mais eficientes para ensinar os conteúdos aos alunos. Inserir as tecnologias nessa perspectiva é o mesmo que não o utilizar, pois, animar a aula ou o professor, ilustrar os conteúdos, simplesmente chamar a atenção dos alunos pela visualidade e sonoridade se resume apenas a um uso instrumental que "esvazia esses recursos de suas características fundamentais, transformando-os apenas num animador da velha educação, que se desfaz velozmente uma vez que o encanto da novidade também deixa de existir" (PRETTO, 1996, p. 114).

Na concepção da racionalidade instrumental, o ensino de história continua sem modificação, apenas com um verniz da modernidade, apresentando os mesmos fracassos escolares anteriores, reproduzindo sujeitos alienados. Considera-se que o uso do computador para fins instrucionais é uma subutilização questionável, pois não basta introduzir os recursos tecnológicos para que se operem mudanças na escola. Ainda que sua presença seja importante, não é suficiente para garantir a qualidade da educação. 
Portanto, um novo fazer pedagógico e historiográfico implica, por parte dos professores, uma reformulação de atitudes e práticas voltadas à utilização das novas tecnologias, mas de forma que sejam apropriadas para "além do domínio de seus comandos e recursos, ultrapassando seus limites técnicos" (CARNEIRO, 2002, p. 111).

A simples incorporação das TIC não gera processos de inovação, nem mesmo de melhoria do processo de ensino e aprendizagem. "A utilização dos recursos das tecnologias de informação e comunicação pela escola não garante mudanças na qualidade da educação. É necessário repensar os paradigmas existentes para adoção de novas práticas educativas" (GOMES, 2002, p. 120).

É por esses motivos que o uso do computador é questionado, sendo necessário que se debatam as implicações no ensino de história e as mudanças na postura do docente em seu uso. Em outras palavras, o que de fato modifica é a forma como os professores delas se apropriam e as utilizam na prática pedagógica para que os processos sejam alterados (COLL; MAURI; ONRUBIA, 2010).

Apesar dos avanços nessas questões, pode-se afirmar que o uso instrumentalista das tecnologias ainda continua dominante no ensino de história, independentemente da existência de propostas diferenciadas, que se podem considerar um passo para a transformação futura.

Com raras exceções, porém, a implantação das novas tecnologias de comunicação e informação na educação, especificamente no ensino de história, tanto pelos governos federais quanto estaduais ou setores privados, lamentavelmente ainda é entendida como simples instrumento didático, "somando-se à perspectiva de que a educação modernizante deve fornecer um ensino técnico acerca dos princípios básicos da informática, criando assim uma mão-de-obra especializada" (NOVA, 1999, p. 84).

Mesmo que hoje o computador seja absolutamente popular, Nova (1999) explica que no ensino a sua função não está clara para os professores. Entretanto, segundo Ferreira, é preciso: 
[...] habilitar os docentes para a utilização didática das NTIC revela-se sine qua non para o desenvolvimento de sua prática pedagógica no mundo atual. Assim, é importante que a formação docente enfoque a incorporação crítica destas ferramentas como ponto central para sua utilização no universo educativo (FERREIRA, 2004, p.61).

Somente quando essas máquinas forem entendidas na escola, e a partir de novas práticas pedagógicas, é que se estará enfocando a aprendizagem dos alunos e desenvolvendo uma pedagogia de inclusão, contribuindo para a melhoria da qualidade na formação.

Frente às questões apresentadas, as reflexões aqui tratadas são parte da pesquisa que alicerçou a dissertação de mestrado da autora, orientada pelo coautor, em 2009, intitulada "Possibilidades e limites na construção do conhecimento histórico em conexão com o mundo virtual", que buscou investigar empiricamente como a inserção dessa ferramenta na atualidade vem acontecendo nessa disciplina e, ainda, como está ocorrendo o processo de formação continuada de professores no estado do Paraná quanto à adoção dessa tecnologia no processo de construção do conhecimento escolar de história.

\section{Novas tecnologias no ensino de história}

Dentro da problemática que envolve o ensino de História e o uso do computador, propusemo-nos as seguintes questões:

- Os professores utilizam os computadores como ferramenta no processo de construção do conhecimento histórico escolar?

- Que suportes e apoios têm à sua disposição em relação à escola e às políticas públicas educacionais para o uso dessa ferramenta pedagógica?

- Quais limitações mais dificultam a condução de um processo pedagógico profícuo por intermédio desta ferramenta?

Embora estas questões sejam complexas e respondê-las exija um conjunto de reflexões, ressaltamos alguns elementos que, nos limites desta reflexão, por ora são pertinentes ao debate, tais como o fato de ser importante que no ambiente escolar, além de recursos tecnológicos, haja professores que façam uso do computador de forma crítica. Afinal, quando falamos no uso das tecnologias nesse fazer não se trata de pensar 
No final da década de 1990 e a partir de 2000, o computador passou a ser adquirido não somente por e para as empresas, mas também para uso pessoal, chegando até as residências e às escolas pela acessibilidade, contribuindo razoavelmente para isso a redução gradativa dos valores desta ferramenta. Ao mesmo tempo, começou-se a debater sua introdução no ensino, em particular a partir do momento que se começou a criar "softwares de banco de dados relativamente amigáveis e baratos" (SILVA, 1998, p.168).

Nesse período, implantaram-se as novas Diretrizes e Bases da Educação Nacional, aprovadas pela Lei $n^{\circ}$. 9.394/96, que trouxe à tona artigos relacionados à ciência e à tecnologia. O art. 39 oferece uma abertura clara ao se referir a uma "[...]educação profissional, integrada às diferentes formas de educação, ao trabalho, à ciência e à tecnologia (Art. 39)." Assim é que os equipamentos computacionais chegaram ao ambiente escolar (FERREIRA, 2004, p.15).

Posteriormente, as máquinas se inserem nas escolas através de projetos e políticas públicas, como o Proinfo (Programa Nacional de Informática na Educação), adotado na rede estadual de ensino, implantando laboratórios de informática como subsídio ao processo de ensino e aprendizagem.

Portanto, os computadores chegam às escolas. Sua implantação altera os aspectos do cotidiano, mesmo sendo mínima a sua utilização, por razões como a necessidade de "adaptação do espaço físico, da grade curricular, os imprevistos técnicos, a curiosidade dos alunos, sem falar nas transformações, [que] quando se utiliza este recurso, parecem provocar alterações, adaptações, fascínio, medos e incertezas" (FERREIRA, 2004, p. 16).

O que constituiu problema foi muitas escolas terem implantado o laboratório de informática por iniciativa do governo, passando o computador a fazer parte do ambiente escolar sem que antes se tivesse definido uma metodologia sobre a prática pedagógica a partir do uso dessa ferramenta. O que se vê, em secretarias e bibliotecas das escolas, é 
devidamente os docentes. É curioso deparar-se com máquinas novas, sem uso eobsoletas por conta do tempo.

Tais laboratórios, quando utilizados, se têm prestado a simples atividades de informática em que os alunos aprendem o funcionamento e a utilização dos programas do pacote do Office. Essa forma de "uso da informática, [...] como estratégia de animação ou como substituta de aulas, acaba reforçando o caráter tradicional da educação, baseado na transmissão de conhecimentos para que os alunos os assimilem de forma passiva" (NOVA, 1999, p. 83). Portanto, percebemos, nas falas dos professores de história, que a mudança tem sido lenta, tendo em vista que tais ferramentas ou ainda não foram incorporadas em suas práticas pedagógicas, ou por prevalecer um uso inadequado no processo de construção escolar de história. Entre as causas desse problema está a própria formação do professor, além da concepção dominante de que a introdução do computador na sala de aula poderia dispensar sua presença.

Há, conforme Libâneo (1998, p. 68), “[...] temor pela máquina e equipamentos eletrônicos, medo da despersonalização e de ser substituída pelo computador, ameaça ao emprego, precária formação cultural e científica ou formação que não inclui a tecnologia”. Postura questionável, já que o computador é apenas um meio que por si só "não vai a lugar algum", já que para ser iniciado ou fornecer dados, precisa dos comandos do professor (REIS, 2006).

Daí a necessidade de desmistificar a ideia de que os professores seriam substituídos pela máquina, uma vez que a eles caberia avaliar como, quando e de que forma realizar a aprendizagem de um conteúdo que poderia ser apreendido pelos alunos. Neste contexto, é necessário voltar o olhar para a formação inicial e contínua dos professores de história, priorizando a prática pedagógica, o fazer historiográfico em comunicação com as novas tecnologias, compreendendo-as como potencializadoras da construção do conhecimento escolar de história de forma a propiciar uma aprendizagem significativa. 
Considera-se que o computador possui muitas potencialidades no ensino e contribui de forma relevante nas pesquisas históricas; ao utilizá-lo em sala de aula, porém, deve-se atentar para a melhor metodologia de ensino. Isso envolve mudanças complexas no sistema educacional de ensino, como a reestruturação dos currículos, a formação inicial e continuada dos professores e a inserção de equipamentos tecnológicos, softwares e acesso à internet com os esperados subsídios para uma mudança de processo gradual e eficaz na prática pedagógica.

Em vários setores educacionais, para a transformação substancial do ensino, tornam-se essenciais ações que envolvam políticas públicas educacionais e disposição de participação efetiva dos sujeitos envolvidos no processo de ensino e aprendizagem.

\section{Perfil dos professores pesquisados e de suas posturas em relação ao uso do computador no ensino: um diálogo}

No intuito de responder à problemática da discussão proposta neste artigo, apresentamos a seguir as questões e as análises das respostas dos professores de história que participaram da pesquisa no estado do Paraná: 51 professores da educação básica, pertencentes a 18 cidades, abrangendo 49 escolas do sistema público e 12 pertencentes ao ensino particular ${ }^{1}$.

Quanto ao perfil, identificamos que $78,43 \%$ dos professores se encontram na faixa de 30 a 50 anos de idade e contam com mais tempo de atuação no magistério. No que diz respeito a gênero, 38 são do sexo feminino e 13,do masculino.

Sobre formação, os dados revelaram que $67 \%$ se formaram em universidades públicas e apenas 33\% em instituições particulares. E ainda, 83\% possuem pós-graduação. Quanto ao tempo de formação, 66\% dos professores são formados de11 a 20 anos, enquanto 12\%atuam há mais de 20 anos.

Em relação à atuação em sala de aula no ensino de história, apenas 17\% contam até 10 anos de tempo de trabalho;66,66\% exercem a docência de 11 a 20 anos; 15,68\% contam

\footnotetext{
${ }^{1}$ A pesquisa tinha como objetivo investigar professores da rede estadual de ensino; porém, 12 professores também trabalhavam na rede particular.
} 
mais de 21 anos de trabalho.

Os dados apresentados até aqui permitem fazer algumas considerações importantes; dentre elas, destaca-se o fato de os professsores, em sua maioria, terem iniciado sua profissão num período pós-ditadura militar, quando a renovação historiográfica e o ensino de história estavam em constantes discussões, principalmente acerca da construção do conhecimento escolar de história. Essa realidade poderia propiciar a eles uma atuação no magistério voltada a novas concepções de história e de transformação dos modelos tradicionais de ensino, contribuindo para o surgimento de novos conceitos, abordagens e metodologias de ensino.

Quanto ao uso do computador, todos responderam que fazem pesquisa para preparar suas aulas. Acreditamos que tal fato constitua um avanço significativo, pois, dessa forma, acreditam utilizar a pesquisa para aprimorar a prática pedagógica. Além disso, $100 \%$ dos professores responderam que utilizam o computador para simples digitação de textos ou preparação de slide sem preparação às aulas, além de outros usos como simples ferramenta tecnológica. Tal realidade pode indicar que o professor, pelo acesso à máquina, sente segurança em utilizá-la com os alunos, pois somente $5,88 \%$ responderam que raramente a utilizam.

A totalidade dos pesquisados não teve contato com a informática na graduação, o que pode levar a outra pergunta: o conhecimento da ferramenta é suficiente para sua mediação pedagógica?

Entre os professores, isto não é uma tarefa fácil, fato que leva 80,39\% deles a considerar necessário inserir uma disciplina na estrutura curricular voltada à informática no ensino de história. No entanto, $15,69 \%$ não a consideram necessária. Buscando identificar este segmento da amostragem, verificou-se que metade já utiliza a ferramenta, enquanto a outra metade simplesmente não trabalha com ela em sua prática pedagógica.

Embora esse percentual não pareça revelador ou tão representativo, pode ao menos indicar que não ter acesso à ferramenta não é exatamente o que leva o professor a negar a necessidade desta formação na sua graduação. Isto porque os professores que o utilizam afirmam não ser necessário e, no conjunto de outras questões por eles 
A maioria, porém, admite a necessidade dessa disciplina na estrutura curricular do curso de licenciatura em história. O motivo alegado é que em didática não tiveram acesso a questões sobre o uso das novas tecnologias, especificamente o computador e, por consequência, à informática. Ou seja, informam que na graduação não tiveram o menor contato com as ferramentas tecnológicas, tanto nas disciplinas específicas (as de conteúdo específico da história), quanto nas direcionadas à atuação profissional (como metodologias e didática).

Este fato, embora possa ser justificado pelo período de formação dos professores, tempo em que a informática na universidade era incipiente e o acesso às máquinas era restrito, dado o elevado seu valor de aquisição em relação à atualidade, também pode ser associado a uma não-compreensão ou compreensão limitada das potencialidades dessa ferramenta para fins pedagógicos, já que as transformações das tecnologias foram exacerbadamente mais intensas do que a capacidade de qualificação profissional demonstrada pela universidade na formação e da escola na formação continuada dos professores. Hoje, este fenômeno é ainda mais impactante e evidente.

A questão é que inserir uma disciplina no currículo do curso de licenciatura em história não garante diretamente a sua eficácia; além disso, se tal inserção se restringir a uma preocupação tecnicista, a discussão se limitará por se reduzir a um fim em si mesmo, enquanto que, se o curso de graduação incorporar as tecnologias no contexto do currículo de forma sistemática e reflexiva, o professor terá uma oportunidade concreta de explorar suas potencialidades e as múltiplas possibilidades de seu uso na construção do conhecimento escolar de história como aprendizagem significativa.

Outra situação que a pesquisa revela, e que é muito contundente para o todo das reflexões, é que os professores em início de carreira que não utilizam essa ferramenta em suas aulas apresentam o mesmo perfil dos formados há muito mais tempo, confirmando não ser esta uma questão apenas de idade, de acesso restrito ou amplo ao universo da 

formação, mas que não seja dissociada da epistemologia da história.

Mais do que equipar as universidades, é necessário inserir atividades que envolvam as novas tecnologias e, ainda, que estejam pautadas por inserções contextualizadas e constituam uma unidade, que, no caso dos cursos de história, envolva, relacione e possibilite dialogar o saber historiográfico e o pedagógico imbricados em seu fazer.

Sabemos que a universidade não pode ficar alheia às transformações, pois é o local de formação dos professores. Ferreira (2003) ressalta a importância de se estabelecer um elo entre a historiografia e a formação pedagógica, no aspecto teórico e prático, para que essa formação docente incorpore conteúdos históricos e pedagógicos e não mantenha distância entre teoria e prática, oferecendo novas abordagens metodológicas. A inserção desta ferramenta, portanto, ampliará as possibilidades de trabalho, pois a escola desenvolve uma prática educativa durante um período contínuo na vida das pessoas. Melo (2006, p.153) afirma que "parece ser necessária a constante formação docente, na perspectiva de fortalecer ou provocar processos de mudança no interior das instituições formadoras".

Devido à importância que as máquinas computacionais passaram a exercer na formação do graduando e em sua vida profissional, algumas universidades já estão buscando alterar seus currículos para atender a essa demanda da sociedade.

Tal inserção acontece através da criação de disciplinas e linhas de pesquisas voltadas à questão do ensino de história articulado com o uso do computador em sala de aula. Como exemplo a citar, a Universidade Católica da Bahia foi a primeira a discutir um novo currículo de história aliando o conhecimento histórico às novas tecnologias. Segundo Figueiredo (1997, p. 433), foi constituída uma disciplina específica na qual se “propõe uma orientação básica, seguida de aplicação pelos próprios alunos de soluções aos problemas e, finalmente, reuniões em que são supervisionados os problemas." 
O mesmo pesquisador acrescenta que também na Universidade de Santa Catarina, no curso de pós-graduação, foi implantada uma linha de pesquisa sobre história e informática, constituída por quatro disciplinas, totalizando 12 créditos: "Introdução à História e Computação; Computadores Pessoais e Pesquisa Histórica I; Computadores Pessoais e Pesquisa Histórica II; Computadores Pessoais e a Comunicação do Conhecimento Histórico." É interessante notar que o trabalho com estas novas disciplinas exige do historiador conhecimentos que extrapolam sua área específica, o que o remete ao diálogo com outras áreas.

Ciampi (2003) considera que tal postura se justifica tendo em vista que estamos diante de novas exigências para o ensino de história e a educação de um modo mais amplo, o que implica pensar na necessidade de se partir do princípio da interdisciplinaridade. Esta ideia está ligada à interação das diferentes áreas do conhecimento e não é simplesmente a uma justaposição dos conteúdos, pois aumentar os horizontes disciplinares pode contribuir para trabalhar com novos objetos de pesquisa.

São registros que revelam um movimento ainda tímido em relação ao impacto das novas tecnologias na contemporaneidade, mas num contexto em que podemos verificar que várias instituições universitárias já estão envidando esforços no sentido de as articular propostas em seus currículos, de modo a se habilitarem para as transformações sociais.

Quanto aos professores que utilizam o computador diretamente na prática pedagógica, metade dos que participaram da pesquisa respondeu, no questionário, que usam a ferramenta no processo de construção do conhecimento escolar de história.

O levantamento revelou dois grupos distintos. Essa diferença se reflete também nas demais questões do questionário. A opção em dividir o grupo pelo critério de utilização do instrumento ajuda a entender as especificidades de cada um no que diz respeito ao porquê da adesão ou não ao uso computador em suas práticas pedagógicas. A amostra da pesquisa em dois grupos - utilizadores e não-utilizadores - tornou possível identificar um perfil específico para cada um deles. Desse perfil, ressalta-se a atenção para 
Do conjunto dos participantes, pode-se afirmar que, proporcionalmente, quanto maior a carga horária, menor o número daqueles que utilizam o computador. Isto pode estar relacionado ao tempo disponível para a preparação das aulas, uma vez que o número excessivo de aulas se impõe como fator limitante das condições de preparação, sobretudo no tocante à utilização de diferentes recursos pedagógicos.

Quando atentamos para a questão de acesso ou não à formação continuada, a pesquisa não revela grandes diferenças entre ambos os grupos, até por certa homogeneidade entre eles. Este fato, porém, levanta uma dúvida: não seria o problema da formação inicial ou contínua do professor de história um fator limitante do uso dos computadores? Geralmente a formação continuada é associada ao caminho que leva à reflexão teórico-metodológica da prática pedagógica, que inclui os recursos programados - incluída, neste caso, a possibilidade de uso da ferramenta computacional.

Contudo, no caso específico desta pesquisa, mesmo os professores com pósgraduação admitem não se apropriar desta ferramenta para suas atividades escolares. No entanto, não significa que possam desconsiderar a necessidade da formação continuada, mas apenas problematizar o caso específico.

Assim, encontraram-se professores com pós-graduação tanto em história quanto em outras áreas que também não fazem uso destas ferramentas em sala de aula. Embora esta observação não explique a ausência ou dificuldade de inserção de novas tecnologias na escola, o computador, no caso, indica que a adesão depende de outros fatores que vão além da questão da formação continuada. Daí emergiu a conclusão acerca da necessidade de os programas públicos trabalharem no sentido de construir uma cultura de formação continuada sistemática e articulada com as necessidades de um fazer pedagógico e historiográfico de qualidade, não se limitando a ser um conjunto de cursos desarticulados, preocupados apenas em suprir uma carga horária, cumprir um programa ou uma agenda política que reivindique a disciplina. 
Do total de 26 professores de história que declararam utilizar o computador em suas aulas, apenas um disse frequentar o laboratório de informática de uma a duas vezes por semana; quatro declararam fazê-lo uma vez por semana. O maior índice relativo a essa frequência foi o de oito docentes, que disseram utilizar com seus alunos o referido laboratório uma vez por mês. Pudemos, ainda, identificar que apenas três professores fazem uso dessa ferramenta uma vez por bimestre. A partir desses dados, serão apresentados os motivos por eles alegados para frequentar tão pouco o laboratório de informática com seus alunos.

Considerando a observação colocada por um deles a respeito de tão escassa frequência ao laboratório (uma vez por mês) - "o uso é controlado pela equipe pedagógica, para que não haja abuso ou mau uso" -, podemos estabelecer várias associações ligadas à estrutura e funcionamento da própria escola.

Para enfatizar a questão, vale resgatar como funciona a organização das escolas no Paraná, nas quais atuam esses professores. O Paraná, desde a década 90, vem estabelecendo políticas de inserção de tecnologias na escola. No início, ocorreu pela implantação de laboratórios de informática nas escolas com maior número de alunos e nas cidades-polo do estado.

Já nos últimos seis anos, na gestão de um mesmo governo, esta política foi ampliada, juntamente com outras do governo federal. Dentre os projetos implantados, destaca-se o Programa Nacional de Informática na Educação (Proinfo²), responsável pela disseminação da informática nas escolas.

O governo paranaense, por sua vez, nos últimos anos, não só ampliou em quantidade o número de escolas atendidas e de máquinas instaladas, mas também tem oferecido um suporte para atendimento aos professores por meio do Núcleo Regional de Ensino. Contudo, o número de máquinas é geralmente inferior à demanda das escolas, já que a distribuição dos equipamentos depende mais do número de professores na escola

\footnotetext{
${ }^{2}$ O Programa Nacional de Informática na Educação (Proinfo) é desenvolvido pela Secretaria de Educação a Distância, em parceria com governos estaduais e municipais, destinado a introduzir as tecnologias de informática e telecomunicações - telemáticas - na escola pública.
} 
Outra questão diz respeito à orientação do uso das máquinas. Conforme a fala de uma das professoras entrevistadas, os "computadores não são para os alunos, é para o professor preparar as aulas e gravar no pen-drive (na hora-atividade); são orientações do NRE”.

Como o Estado equipou as salas de aula com TVs adequadas ao uso dos pen drives, os professores são o público-alvo do programa. Ou seja, os computadores são para que eles pesquisem, preparem materiais didáticos e textos, para, posteriormente, trabalhar em sala com o auxílio da TV.

Este fato entra em conflito com o discurso da própria Secretaria da Educação que, via mídia, diz que a escola está equipada com computadores e os alunos têm acesso à tecnologia. Na prática, porém, o uso do laboratório seguiu sendo apenas para os professores e as tais "informações" por eles preparadas continuam sendo apresentadas da forma expositiva e tradicional, mudados apenas os "recursos tecnológicos".

Outras dificuldades e limitações de diferentes naturezas quanto ao uso do computador no ensino de história foram identificadas na resposta dos professores. Entre elas, falta de equipamento, indisciplina e despreparo no manuseio do equipamento. Quanto à falta de equipamento, a questão é que as máquinas chegam à escola de acordo com os números de professores da instituição. O documento do Conselho Regional de Tecnologia Educacional (CRTE) deixa claro que os computadores são primeiramente para os professores; por isso, não são distribuídos em quantidade que permita seu uso direto pelos alunos.

A instrução do Núcleo Regional de Educação do Município de Londrina e região contradiz frontalmente a fala do secretário de Educação do Estado do Paraná, apresentada nos meios de comunicação. Ele ressalta que todas as escolas estão ligadas à internet e com laboratórios disponíveis para os estudantes, enfatizando que estes são construídos para atender às suas necessidades. 
Na verdade, não funciona desta forma. Segundo o documento do CRTE, "[...] a quantidade de terminais e mobiliário do PRD existe em função do número de professores que compõem o quadro docente do estabelecimento [...]”.

O governo, com isso, não apresenta a realidade escolar, pois os professores não estão conectados com seus alunos e muito menos adequadamente preparados para o uso desta tecnologia. Além disso, o quadro descrito se agrava ainda mais no sentido de dificultar quando se deparam com outros problemas e dificuldades no cotidiano escolar, entre as quais os inúmeros procedimentos burocráticos, as regras e responsabilidades encontradas e exigidas na escola, que limitam seu uso.

Um exemplo disso é um termo de responsabilidade enviado pelos Núcleos Regionais de Educação do Paraná, que confirma a responsabilidade do professor em levar os alunos ao laboratório. No documento fica expresso serem eles os únicos a assumir toda a responsabilidade pelo uso dos equipamentos. Sem querer negar o cuidado que qualquer usuário deve ter com o patrimônio público, não há divisão de responsabilidade com os alunos - os reais os usuários -, nem mesmo com a escola, entendida como órgão com o qual outros entes devem contribuir e colaborar para possibilitar e facilitar a realização das atividades pedagógicas.

Estes fatos contribuem significativamente, e por que não, decisivamente, para desestimular e quase inviabilizar o uso dos computadores pelos professores, já que as condições de trabalho são realmente adversas: há mais alunos do que máquinas; não há um laboratorista que dê suporte às atividades e, sobretudo, há um número de alunos desproporcional à capacidade de acompanhamento do professor sem prejuízo do “espaço de aprendizagem” e, especialmente, da possibilidade de efetivação das atividades pedagógicas.

Outra questão importante diz respeito à organização do trabalho de apoio aos professores de história do estado do Paraná. Geralmente, a equipe pedagógica da escola (supervisão, orientação e direção) é orientada pelo Núcleo Regional de Educação da seguinte maneira: é necessário o professor elaborar um plano de aula antecipado e apresentar à equipe pedagógica para análise e aprovação antes de utilizar o laboratório 
atividades burocráticas que cabem ao professor no sistema de ensino. Tal fato é apontado como desmotivador.

Afirmar que a exigência de planejamento nesses moldes é desmotivadora não significa entender tão somente que planejar seja dispensável, mas que o plano deve ser incentivado e facilitado de forma que o professor não passe a ideia de "uma imposição". Esta precaução vale para atividades com ou sem a tecnologia do computador, especialmente por se tratar de uma proposição em formato aberto, pela qual o professor possa imprimir identidade própria à sua construção.

Como pudemos então verificar, são várias as dificuldades encontradas pelos docentes, desde as de ordem teórico-metodológicas, até as operacionais e burocráticas. Estas são realmente questionáveis. De fato, não se pode pensar que um professor deva gastar mais energia com problemas desta ordem do que com questões pedagógicas, pois isto impede, por desmotivação, que eles descubram as potencialidades do computador para tornar mais fácil, interessante, prazeroso e significativo seu fazer, tanto para ele como para seus alunos.

\section{Formação continuada como iniciativa do poder público: teoria ou prática?}

Sendo o computador uma tecnologia de uso ainda recente, quando se trata dessa questão no espaço escolar, a formação continuada dos professores pode ser um meio para compreender e, especialmente, para alavancar o processo de inserção das novas tecnologias no ensino atrelado às metodologias do ensino de história. Tal afirmação nos leva a questionar: Os professores de história participam de formação continuada? Como é essa formação? Apenas para uso instrumental ou pautado na perspectiva de uma abordagem construcionista de educação?

Nesta pesquisa, os professores indicaram haver programas de formação nesta linha de trabalho vinculados ao Proinfo; 35,29\% deles afirmaram que fazem cursos com os 
o uso do computador na escola; há uma distância entre a proposta do governo e a prática na escola; a atuação do NTE é efêmera e circunstancial, ou seja, insuficiente.

Pelas respostas ao questionário, 17 dos professores que utilizam o computador na sala de aula não tiveram apoio do NTE; mesmo assim, utilizam do computador. Em contrapartida, nove dos que não o utilizam, receberam apoio do núcleo, mas nem por isso alteraram sua postura frente às novas tecnologias. Este dado indica que aqueles que utilizam o computador não foram diretamente influenciados pelo programa de assessoria do NTE, mas por postura própria frente à prática pedagógica.

Os profissionais que trabalham nos núcleos são capacitados pelo Proinfo para ajudar a instituição escolar em todas as fases do processo de incorporação das novas tecnologias. Portanto, o NTE atua na escola no processo de inclusão digital, orientando professores e alunos quanto ao uso do computador no laboratório de informática, bem como no que se refere à manutenção do equipamento. Sua função é orientar sobre o uso desses instrumentos para promover o desenvolvimento dos alunos e a alcançar bons resultados, não apenas na escola.

$\mathrm{Na}$ prática, entretanto, o que pudemos inferir dos dados coletados é que se limitam a auxiliá-los na questão técnica da informática e que em nada contribuem especificamente para a prática pedagógica do profissional de história. Não se propõe aos professores de história uma metodologia própria, senão a mesma para os professores em geral, independente da área em que atuam, o que induz a admitir que os métodos de trabalho são iguais para todas as disciplinas. Neste sentido, podemos caracterizá-los como cursos de informática sobre a técnica para trabalhar com as máquinas.

Esta constatação, por isso, conduz à seguinte questão: embora o estado do Paraná tenha uma política de inserção de novas tecnologias nas escolas, com grupo de assessores técnicos específicos, não pudemos verificar uma mudança de fato na postura dos professores, já que todos estão sendo treinados de forma generalista e tecnicista, e 
como um fim em si mesmo e não como meio para alcançar as propostas na melhoria do ensino; neste caso, o de história.

O fato é que, mais uma vez, se confirma a contradição entre o discurso do Estado e os depoimentos dos professores. Não há propriamente um curso de formação continuada, mas apenas assessores pedagógicos e técnicos para ir à escola e, ainda, quando solicitados pela instituição escolar para sanar as dúvidas técnicas e orientar os professores sobre funcionamento do computador, como digitação, salvamento de arquivos, construção de slides para apresentação em aula, transferências de músicas, imagens e semelhantes. Mais, tais operações são para aqueles professores que já possuem certo domínio básico em relação à máquina; caso contrário, limita-se ainda mais à simples digitação. Portanto, há uma distância entre este grupo técnico, a realidade da escola e a necessidade do professor de história. Mas, pergunta-se, em que sentido?

Ocorre que o agendamento deve ser feito antecipadamente. O núcleo também não tem apenas uma escola para atender; ao contrário, é uma equipe para atender a uma série de instituições escolares, enquanto as dúvidas surgem no cotidiano da prática e a demora em obter as respostas acaba por desestimular a própria consulta e, consequentemente, o uso do equipamento. Some-se a isso o fato de que as visitas técnicas são ocasionais. Não há um trabalho contínuo na escola e, em particular, com os professores de história, fato que se reflete em suas falas, com as quais justificam a ineficácia da atuação do NTE justamente pela brevidade dos cursos e o pouco tempo de atendimento do funcionário do Núcleo Regional de Educação.

Tudo isto leva a refletir em duas direções: a primeira, a de identificar a necessidade de uma política do Estado mais consistente com tal finalidade; a segunda, na relação entre a intervenção do Estado nesta formação e a própria autonomia do professor quanto à sua formação. 
No caso da escola pública, há sempre um forte apelo ao Estado para ampliar e melhorar as políticas voltadas à educação; entre elas, as relacionadas à formação continuada do professor. Isto é certamente válido e necessário, pois o investimento na formação continuada do professor é um dos caminhos para melhorar o ensino de história. Contudo, essa política só será sólida se os programas contarem com a própria demanda dos professores e não por imposição hierárquica, mas num sistema de construção conjunta de processos formativos, em que os professores sejam ouvidos, suas experiências consideradas e compartilhadas com o grupo e motivados a participar efetivamente dos programas.

Por outro lado, também há que se pensar na autonomia que o professor deve ter quanto à própria qualificação. Ou seja, não se pode pensar em um educador que fica à espera de uma proposta apenas externa, seja do Estado, seja da iniciativa privada. Ele mesmo deve estar à frente do seu tempo e buscar respostas para suas dúvidas, inquietações cotidianas e, sobretudo, constituir-se sujeito de sua própria formação.

É neste sentido que esta pesquisa procurou estimular um repensar no ensino de história, a partir da valorização da busca pelo próprio professor e da importância de sua autonomia nesse processo para fazer frente às mudanças tecnológicas que vêm ocorrendo em nossa sociedade e seus múltiplos desdobramentos, especialmente ao se dar conta de seu envolvimento na formação de pessoas também autônomas, dialogando com elas sobre a reprodução da vida, as necessidades e incertezas vividas em sociedade.

Nas palavras de Paim (2007), tais mudanças devem ocorrer pela postura do "fazerse professor", bem como pela partilha de experiências cotidianas, dos processos de lutas, conquistas, memórias, em que os educadores passam a ser sujeito do processo de mudança e construtores da sua própria história.

Para que se efetive na prática esta sua autonomia, é de suma importância que a escola rompa com a divisão dos saberes. E isto só é possível a partir do momento em que se debata a importância da participação desses professores e se tornem públicas as discussões com os setores dirigentes para apresentar suas divergências e suas posições na busca de soluções conjuntas. Sublinhamos, ainda, a necessidade de debates 


\section{Considerações finais}

Com as pesquisas e a partir delas, pudemos entender que a utilização dos computadores pelos professores de história nas escolas investigadas tem ocorrido de forma alheia às necessidades da comunidade escolar, principalmente por falta de condições de preparo antecipado dos docentes para utilizá-los no processo de construção do conhecimento escolar de história.

Um dos fatores que favorecem esta realidade envolve também a responsabilidade do Estado em fornecer equipamentos tecnológicos às escolas, acompanhada de uma boa formação historiográfica e metodológica do professor para tal articulação. Isto porque, se o docente não tiver base sólida da concepção de história que irá nortear seu trabalho em sala de aula e conhecimento de como relacioná-la a uma metodologia definida, acabará limitando as possibilidades de uso dessa ferramenta pedagógica no ensino da disciplina.

Além disso, verificamos que a abordagem, na maioria das vezes tecnicista, da utilização das novas tecnologias no ambiente escolar, no estado do Paraná, tem ocorrido de forma rápida, atabalhoada, e por isso insatisfatória, sem ser acompanhada da preparação do professor e dos demais envolvidos na efetivação de situações de aprendizagem para os alunos, para que seu uso de fato constitua uma oportunidade pedagógica. Ao contrário, ampliaram-se os projetos das políticas públicas para a implantação do aparato tecnológico. A inserção do computador pode ser considerada, de tal forma, inadequada na condução do processo que nos possibilita inferir que, além de pouco contribuir com os objetivos do ensino de história, possa até desvirtuar a percepção que professores e alunos possam ter de seu uso e de sua função na sociedade como um todo. Esta afirmação se deve ao fato de os professores evidenciarem a não-inclusão digital para todos; à falta de formação pedagógica atrelada ao fazer historiográfico dos 
A divulgação das propagandas governamentais, pelos meios de comunicação, emprega um discurso que escamoteia a realidade ao induzir a uma leitura de que todas as escolas estão equipadas com computadores e à crença de um acesso geral e uniforme à internet. Essas notícias não correspondem aos dados coletados e analisados no universo da pesquisa e são pouco pertinentes ao contexto das escolas investigadas, já que a maioria dos professores de história justificou a não-utilização dessa ferramenta pedagógica, sobretudo em razão de sua falta, tanto por conta de equipamento quanto de laboratório.

O que se percebe neste processo é que a implementação dos sistemas tecnológicos nas escolas não foi acompanhada, em qualidade e quantidade, de um processo metodológico de formação dos professores de história, desconsiderando sua condição de principais sujeitos do processo pedagógico. Deve haver, então, uma retomada, por parte do Estado, desse programa. Voltar o seu olhar prioritariamente para os docentes como correção de rota no processo de inclusão das novas tecnologias, ou seja, propiciar condições de trabalho ao inserir tais inovações na escola e não apenas ampliar as responsabilidades dos professores sem o respaldo adequado para tal.

Esta visão tecnicista e limitada deveria ser substituída por outra em que o centro das atenções fosse o processo de ensino e aprendizagem. Por quanto pudemos verificar, tudo tem sido feito dentro do que há de mais retrógrado e lamentável quando se trata de processos educacionais: a preocupação com a forma sem alteração do conteúdo, no sentido de ressignificar e, assim, aprimorar e atualizar práticas e posturas.

Embora haja uma carência de políticas públicas realmente efetivas, que valorizem o trabalho docente e melhorem qualitativamente as condições de trabalho do professor, também é necessário romper com as práticas pedagógicas inadequadas e descomprometidas com os princípios que devem reger um ensino de história preocupado com o aprimoramento da construção, em curso, da cidadania que na atualidade se deve pautar pela formação de sujeitos autônomos, capazes de dialogar com os processos 
essas transformações no contexto de sua prática pedagógica, buscando a própria autonomia para estar à frente do seu tempo e, sobretudo, para conduzir sua própria formação continuada, visto que as tecnologias de comunicação e informação somente poderão contribuir se o professor tiver uma formação teórico-metodológica de qualidade e se as informações forem transformadas em conhecimento para ele e seus alunos, resultando na melhoria do ensino, a partir da didática da história necessária à formação de pessoas capazes de perceber a dimensão do humano a partir da leitura das humanidades.

\section{Referências bibliográficas}

BITTENCOURT, Circe. (Org.). Ensino de história: fundamentos e métodos. São Paulo: Cortez, 2004.

CARNEIRO, R. Informática na educação: representações sociais do cotidiano. São Paulo: Cortez, 2002.

CIAMPI, Helenice. Epistemologia e metodologia: diálogos interdisciplinares na pesquisa do ensino de História. In: ARIAS NETO, J. M. (Org.). Dez anos de pesquisa em ensino de história. Londrina: Atritoart, 2005.

CIAMPI, Helenice. O processo do conhecimento/pesquisa no ensino de história. História \& Ensino: Revista do Laboratório de Ensino de História. Londrina. Eduel. 2003

COLL, César; MAURI, Teresa; ONRUBIA, Javier. A Incorporação das Tecnologias de Informação e Comunicação na Educação: Do projeto técnico-pedagógico às práticas de uso. In: __ _ _ MONEREO, Carles (Orgs.). Psicologia da educação virtual: aprender e ensinar com as tecnologias da informação e comunicação. Porto Alegre: Artmed, 2010. p. 66- 96.

FERREIRA, Andréia de Assis. Apropriação das novas tecnologias: concepções de professores de história acerca da informática educacional no processo ensino - aprendizagem. Belo Horizonte, 2004. 130 p. Dissertação (Mestrado) - Centro Federal de Educação Tecnologia de Minas Gerais, Cefet- MG, 2004. 
FERREIRA, Carlos Augusto Lima. O Ensino de história nas escolas de ensino fundamental e Médio de Salvador de Bahia: análises de variáveis e a contribuição do computador. Dissertação (Mestrado em Pedagogia Aplicada) - Universitat Autónoma de Barcelona, Barcelona, 1997.

FERREIRA, Carlos Augusto Lima. A formação e a prática dos professores de história: enfoque inovador, mudança de atitudes e incorporação das novas tecnologias nas escolas públicas e privadas do estado da Bahia, Brasil. Tese (Doutorado em Educação) - Universitat Autónoma de Barcelona, Barcelona, 2003.

FIGUEIREDO, Luciano R. História e Informática: O Uso do computador. In: CARDOSO, Ciro Flamarion; VAINFAS, Ronaldo (orgs.) Domínios da história: ensaios de teoria e metodologia. Rio de Janeiro: Campus, 1997.

FONSECA, Selva Guimarães. Didática e prática de ensino de história: experiências, reflexões e aprendizados. Campinas, SP: Papirus, 2003.

FRANÇA, Cyntia Simioni. Possibilidades e limites na construção do conhecimento histórico em conexão com o mundo virtual. Dissertação (Mestrado em História Social) Universidade Estadual de Londrina, Londrina, 2009.152p.

GOMES, Nilma Computador na escola: novas tecnologias e inovações educacionais. In: BELLONI, M. L (Org.). A formação na sociedade do espetáculo. São Paulo: Loyola, 2002. p. $119-134$.

LIBÂNEO, José Carlos. Adeus professor, adeus professora? Novas exigências educacionais e profissão docente. São Paulo: Cortes, 1998.

MELO, Maria do Carmo. Labirinto da epistemologia e do ensino de história: um estudo em Recife. Tese (Doutorado em Educação) - Universidade do Minho, 2006.

NOVA, Cristiane Carvalho da. Novas lentes para a história: uma viagem pelo universo da construção da história e pelos discursos áudio-imagéticos. Dissertação (Mestrado em educação) - Faculdade de Educação - Universidade Federal da Bahia, Salvador, 1999.

PAIM, Elison. Do Formar ao Fazer-se Professor. In: MONTEIRO, Ana Maria (Org.). Ensino de história: sujeitos, saberes e práticas. RJ: Mauad : Fapery, 2007.

PRETTO, Nelson Uma escola com/sem futuro. Campinas, SP: Papirus, 1996.

PRETTO, Nelson; SILVEIRA, Sergio Amadeu . Além das redes de colaboração: internet, diversidade cultural e tecnologias do poder. Salvador: EDUFBA, 2008. Disponível em: <http://rn.softwarelivre.org/alemdasredes/debatedores/nelson-pretto >. Acesso em: 23 nov. 2010. 
REIS, Suzi Cristina. Educação e tecnologia: o computador e a internet como ferramentas pedagógicas. Monografia (Especialização) - Departamento de Educação da UEL/PR, Londrina, 2006.

SILVA, Edson Armando. Banco de dados e pesquisa qualitativa em história: reflexões acerca de uma experiência. Revista de História Regional, v.3, n.2 , p.167-176, Inverno 1998. 